\title{
KAMPANYE KB DI DUSUN MARGAMULYA DESA CIKUNIR KECAMATAN SINGAPARNA KABUPATEN TASIKMALAYA TAHUN 2017
}

\section{OLEH :}

\author{
Happi Apriasih, SST,M.Kes \\ Annisa Rahmidini, SST, M.Keb \\ Chanty Yunie, SST,M.Kes \\ Santi Susanti, SST,M.Kes
}

\section{A. DASAR PEMIKIRAN}

Indonesia merupakan salah satu negara dengan penduduk terbanyak di dunia. Ledakan penduduk ini terjadi karena laju pertumbuhan penduduk yang sangat tinggi. Kondisi ini jelas menimbulkan dua sisi yang berbeda. Disatu sisi kondisi tersebut bisa menjadi salah satu kekuatan yang besar untuk Indonesia. Tetapi di satu sisi kondisi tersebut menyebabkan beban negara menjadi semakin besar. Selain menjadi beban negara juga menimbulkan permasalahan lain. Banyaknya jumlah penduduk yang tidak disertai dengan ketersediaan lapangan pekerjaan yang mampu menampung seluruh angkatan kerja bisa menimbulkan pengangguran, kriminalitas, yang bersinggungan pula dengan rusaknya moralitas masyarakat.

Karena berhubungan dengan tinggi rendahnya beban negara untuk memberikan penghidupan yang layak kepada setiap warga negaranya, maka pemerintah memberikan serangkaian usaha untuk menekan laju pertumbuhan penduduk agar tidak terjadi ledakan penduduk yang lebih besar. Salah satu cara yang dilakukan oleh pemerintah adalah dengan menggalakkan program KB (Keluarga Berencana). Program KB pertama kali dilaksanakan pada masa pemerintahan Soeharto yaitu saat Orde
Baru. Melalui KB masyarakat diharuskan untuk membatasi jumlah kelahiran anak, yaitu setiap keluarga memiliki maksimal dua anak. Tidak tanggung-tanggung, KB diberlakukan kepada seluruh lapisan masyarakat, dari lapisan bawah hingga lapisan atas dalam masyarakat. Oleh sebab itu laporan ini disusun untuk mengetahui seluk beluk mengenai penyelenggaraan $\mathrm{KB}$ di Indonesia, mulai dari sejarah, proses pelaksanaan, kelebihan dan kekurangan dari $\mathrm{KB}$, serta dampak positif maupun dampak negatf dari pelaksanaan KB.

\section{B. TUJUAN}

1. Untuk mengetahui peran dari pemerintah dan masyarakat dalam pelaksanaan program $\mathrm{KB}$

2. Untuk mengetahui gambaran pelaksanaan program KB di Indonesia

\section{BENTUK KEGIATAN}

Kampanye tentang Keluarga Berencana (KB) pada Pasangan Usia Subur (PUS) di daerah desa Margamulya 
D. SASARAN

Seluruh Pasangan Usia Subur (PUS) di daerah dusun Margamulya

E. TEMPAT DAN WAKTU

Hari/Tanggal

Selasa, 23 Maret 2017

Tempat

Madrasah Margamulya

Waktu

08.00 s.d Selesai

\section{F. HASIL KEGIATAN}

Kegiatan yang dilakukan adalah penyuluhan. Materi yang disampaikan adalah tujuan keluarga berencana, tujuan $\mathrm{KB}$ dan jenis alat kontrasepsi disesuaikan dengan tujuan KB.

Kegiatan ini diikuti oleh Pasangan Usia Subur yaitu sebanyak 64 orang. Kegiatan ini meliputi penyuluhan dan pembagian leadlet materi KB.

\section{G. KEPANITIAAN}

Annisa R, SST,M.Keb

Happi Apriasih, SST,M.Kes

Santi Susanti, SST,M.Kes

Chanty Yunie, S.ST,M.Kes

\section{H. DOKUMENTASI}
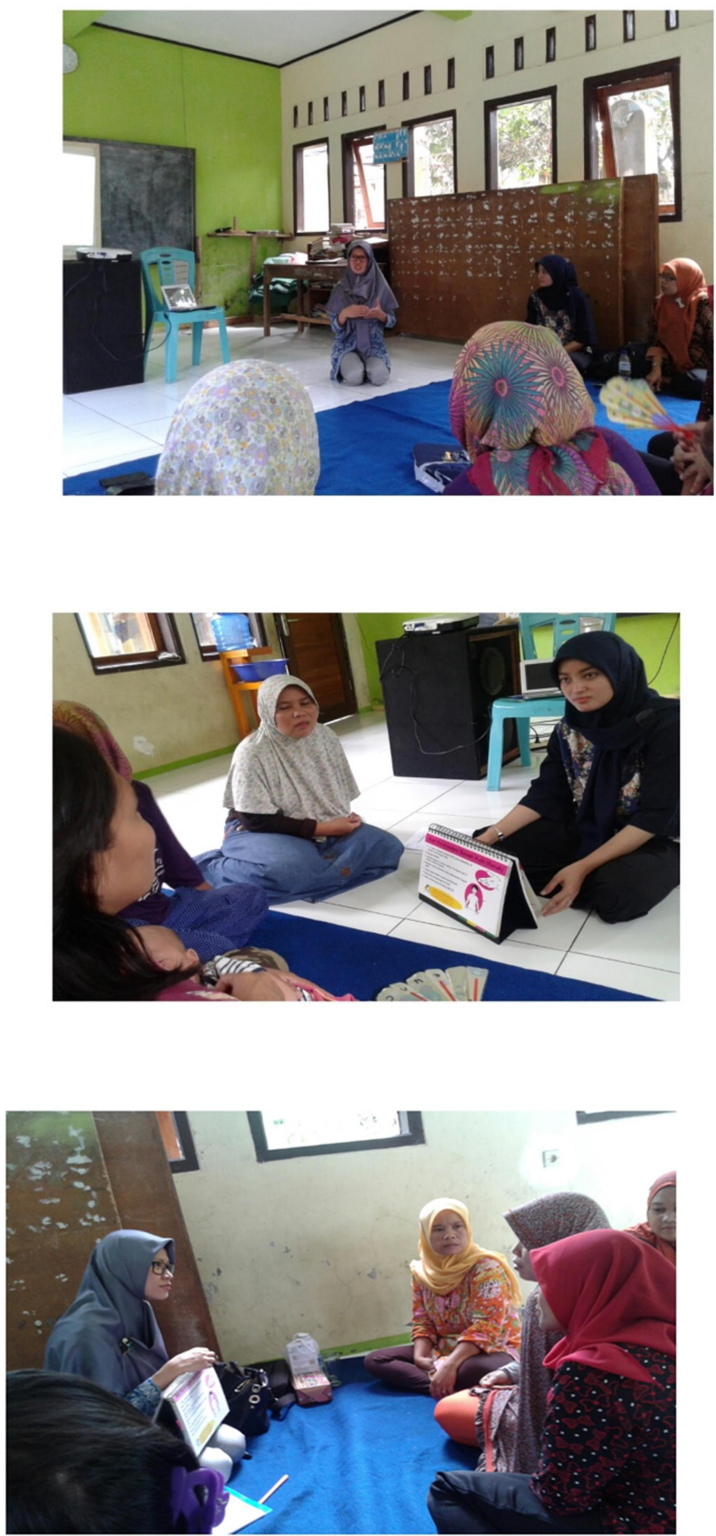